questions or advice, an advice centre where users can sign up to have an online mentor, an employment and research-funding centre for searching available openings or tracking down financial support, and a resource centre for full-text, online reports, such as Reshaping the Graduate Education of Scientist and Engineers, and the new student guide from the NAS.

The McDonnell Foundation home page offers programme information, guidelines for how to apply, and a listing of the grants and awards available from the foundation. The pertinent areas of funding are biomedical and behavioural sciences, including cognitive neuroscience, and research and innovation in education. Of particular interest will be the McDonnell-Pew programme in cognitive neurosciences, as well as a new programme that focuses on collaborative projects in cognitive rehabilitation research.

B.H.

\section{The view from Europe}

EVERY autumn, like migrating geese, thousands of European neuroscientists flock to the annual meeting of the US Society for Neuroscience. Why do they take the time and trouble to cross the Atlantic to submerge themselves in the bewildering crowds of tens of thousands of attendees?

The short answer is that, in contrast to Europe, neuroscience in the United States has a strong identity, a well-organized umbrella society, and its annual meeting acts as the world's largest market for making contacts in the hunt for collaborators or new employment.

Neuroscience in Europe has yet to settle on an identity of its own. The European Neuroscience Association (ENA) is hard pushed to attract 2,000 attendees, despite an estimated population of more than 12,000 neuroscientists. Things tend to happen more often at the national level, where travel to society meetings is cheaper, and scientists have the additional, often-overlooked, advantage of being able to relax and speak their own language. Leading neuroscientists are aware of the lack of cohesion at the European level. In an attempt to inspire political support, the European Commission was persuaded in 1990 to launch a Decade of the Brain initiative, to parallel the well-funded Decade of the Brain in the United States. The initiative was a damp squib, primarily because no new money was made available to support it.

An ad hoc task force of scientists was established to make recommendations for a special brain research programme in the fourth of the commission's 5-year framework programmes (1994-98), but in a burst of unrealistic optimism put forward plans that would have cost around 50 times the entire budget available for the commission's whole biomedicine programme, Biomed.

The proposal was duly rejected although, as a direct result of the initiative, a brain research programme covering basic and clinical research was included in the fourth Biomed framework programme. It receives 12 per cent of Biomed's ECU336 million (US\$415 million) fund, and has proved extremely popular: the first call for proposals early last year attracted 285 applications, mostly from the United Kingdom, France, Germany and Italy, of which 41 were accepted. Neuroscience now also has a special place in the commission's biotechnology programme and will receive 6 per cent of the funds, around ten times more than it received within the third Biotech framework programme.

Things could get even better. The European parliament last month called for a special programme for Alzheimer's disease to be established within the fourth framework programme, but again it is not clear whether or not extra money could be made available for it.

Despite its lack of cohesion, Europe has a very strong base in neurosciences and active national associations. In the United Kingdom, for example, the Brain Research Association last year published a booklet for secondary schools, aimed at encouraging students to apply to study neurosciences at university. The booklet, which schools can use almost as a textbook, has
In fields such as neuroimaging, researchers often find themselves providing a service to those in other disciplines. But these techniques are also advancing knowledge in their own right. The description of precise functionalanatomical correlations is producing new hypotheses about the functional architecture of the brain. In this image, a PET perfusion scan from an activation experiment designed to isolatemental components of upper limb movement is coCognitive Neurology, Institute of Neurology, London.) been a big success, judging from the number of orders received, from as far afield as Australia and New Zealand. But whether it will be successful in increasing active interest in studying neuroscience is harder to assess. Neuroscience, a term coined only 50 years ago, is a diverse discipline, encompassing a wide range of subjects including cell and molecular biology, physiology, pharmacology, psychology, and even information science, and very few British universities offer an undergraduate course bearing the name 'neuroscience'.

This can be seen as both positive and negative, according to Gavin Swanson, editor of the Cambridge-based journal Trends in Neurosciences. One the one hand, because the subject is not entrenched in tradition, neuroscience remains flexible and "ideally placed to respond to market forces" he says. On the other hand, the lack of a strong identity could reduce its lobbying power for limited funds.

This latter point also worries Geoff Bennett, a lecturer at Nottingham University, who runs a group within the British Neuroscience Association to promote neuroscience teaching. But Rudolf Menzel, a professor of zoology at the Free University of Berlin, sees diversification as only an advantage, "because we can get money from a wide range of funding organizations and programmes".

To represent this diversity better, the Brain Research Association, which has 1,400 members, voted in March to change its name to the British Neuroscience Association (BNA) because many members felt the old name inappropriately excluded scientists working on other areas, for exam-

\title{
Initial progress in neuroimaging
}

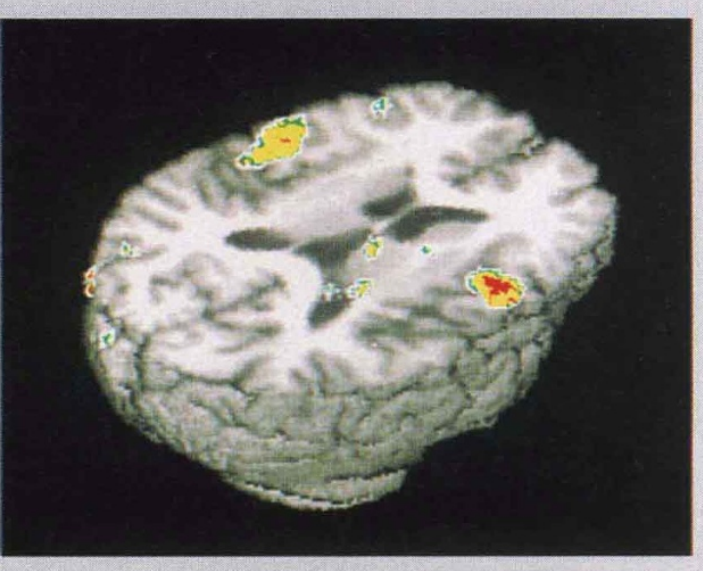
registered with the subject's own anatomical MRI scan. Computer algorithms allow direct assessment of the precise cerebral structures involved. In this case, an imagined movement when compared to attending to the limb to be moved (preparing set), results in the opercular activations bilaterally (among other activations) even though the mental tasks are being directed specifically at the right upper limb. For the first time, such biological correlates of mental activity allow discussion of its nature in scientific terms rather than by introspections and speculation.(Image: Wellcome Dept of 